Issn: 1808 - 799X

ano 10, no 14 - 2012

\title{
INOVAÇÃO TECNOLÓGICA E PROJETO EDUCACIONAL DO EMPRESARIADO INDUSTRIAL BRASILEIRO: UMA ANÁLISE CRÍTICA
}

\author{
Rafael Gomes Cavalcante ${ }^{1}$ \\ Alessandro de Melo $^{2}$ \\ Paulo de Nobrega ${ }^{3}$
}

\section{RESUMO}

Este artigo trata de uma pesquisa teórica que tem por objetivo analisar os fundamentos da relação entre a inovação tecnológica e o papel da educação na formação dos trabalhadores. Busca-se identificar como o capital articula inovação, produtividade e projeto educacional. A fase atual do desenvolvimento capitalista, caracterizada pela acumulação flexível, tem na intensificação acentuada de inovação os seus fundamentos estruturais. O aumento da capacidade de inovação possibilita para a empresa e para o país, segundo o empresariado industrial, a condição de competitividade no mercado internacional, isto porque, entre outros fatores, ela proporciona um salto de produtividade. Trata-se de compreender como esta vinculação entre educação e capital se dá no contexto dos novos paradigmas produtivos, que têm na inovação constante o seu principal pilar de sustentação.

Palavras-Chave: Inovação tecnológica; projeto educacional; empresariado e educação.

\footnotetext{
${ }^{1}$ Pedagogo formado pela Universidade Estadual do Centro-Oeste. Mestrando no Programa de Pós-Graduação em Educação da Universidade Federal do Paraná. E-mail: rafaelgomescavalcante@gmail.com

${ }^{2}$ Doutor em Educação pela UFPR. Professor do Departamento de Pedagogia da Universidade Estadual do Centro-Oeste. Professor do Programa de Pós-Graduação em Educação da UFPR. Email: alessandrodemelo2006@hotmail.com

${ }^{3}$ Doutor em Educação pela UFSC. Professor do Departamento de Pedagogia da Universidade Estadual do Centro-Oeste.Email: panobrega@ig.com.br
} 


\section{Introdução}

A educação institucionalizada tem sido uma importante ferramenta para os propósitos do capital, tanto por fornecer-lhes conhecimento e pessoal necessário à maquinaria produtiva, como por gerar e transmitir um quadro de valores que legitima o interesse da classe dominante. A superação desta função educacional exige como precondição, um profundo conhecimento das formas de determinações sociais relativas ao capitalismo. A educação tem um papel fundamental no desenvolvimento contínuo da consciência de uma transformação social, mas para tanto, se faz necessário que os envolvidos conheçam as formas como o capital vem articulando trabalho e educação, no contexto atual.

O objetivo deste artigo é analisar os fundamentos da relação da inovação tecnológica e o papel da educação na formação dos trabalhadores neste contexto. O problema é identificar como o capital articula inovação, produtividade e projeto educacional.

A pesquisa está fundamentada no referencial marxista e, portanto, busca analisar as relações entre trabalho e educação no contexto da produção contemporânea, caracterizada pela necessidade premente do capital de inovar, ou, como afirmaram Marx e Engels, no Manifesto do Partido Comunista, em 1948, "revolucionar constantemente os meios de produção". No capítulo X do Volume 1 de O Capital, Marx aprofunda a discussão sobre este tema com 0 desenvolvimento da categoria de mais-valia relativa.

O estudo será baseado em análise bibliográfica de autores que estudam o mundo do trabalho e a educação do trabalhador, bem como os documentos da CNI que tratam da questão da inovação.

A fase atual de desenvolvimento capitalista, definida por Harvey (2010) como acumulação flexível, tem na intensificação acentuada de inovação os seus fundamentos estruturais. O aumento da capacidade de inovação possibilita para um país ou para uma empresa, a condição de competitividade no mercado internacional, isto porque, entre outros fatores, ela proporciona um salto de produtividade.

É importante ressaltar que a produção de riqueza está fundada na exploração cada vez maior da força de trabalho, e, por isso, Marx (1989) afirma 
que a produção capitalista não é simplesmente produção de mercadoria, mas, fundamentalmente produção de mais valia.

Portanto, um projeto educacional que articula inovação e produtividade no sentido que as caracterizam no modo de produção vigente - significa uma prática pedagógica que continua a serviço da lógica do capital, como proposta de conformação a exploração.

Numa concepção marxista sobre a função da educação, o sistema educativo é compreendido como um instrumento de luta contra a alienação, como forma de se "[...] decifrar os enigmas do mundo do trabalho, sobretudo, o do estranhamento de um modelo produzido pelos próprios homens" (SADER, 2008 p. 17).

O texto está dividido da seguinte forma: uma primeira parte em que são analisados os fundamentos da reestruturação produtiva na acumulação flexível na contemporaneidade, que é a mediação para a explicação da inovação tecnológica, que é analisa em seguida. Esta análise parte dos pressupostos marxianos encontrados em O Capital, em que o autor analisou o desenvolvimento da produção capitalista e já verificou que a inovação tecnológica, juntamente com as formas de organização do trabalho, era a maneira "natural" do desenvolvimento capitalista, dada a necessidade de extração cada vez mais avançada de mais-valia relativa e absoluta, ao mesmo tempo que crescia a necessidade de controlar a força de trabalho. Nessa mesma parte do texto será desenvolvida uma reflexão sobre a perspectiva do empresariado sobre a formação do trabalhador para o trabalho com as novas tecnologias.

Toda a caminhada do artigo está permeada pelo fato iniludível de que há uma relação estreita entre as mudanças na produção capitalista, a adequação dos trabalhadores aos novos contextos produtivos e, juntamente com estes processos, as mudanças no projeto educativo desde a escola, nas políticas educacionais e outras ações do Estado e da sociedade civil.

\section{Reestruturação produtiva e suas implicações no processo de trabalho}

Segundo Antunes (1999), depois de um grande período de acumulação de capitais, que ocorreu no período pós-guerra, entre os anos de 1945 a 1973, no 
apogeu do fordismo e da fase keynesiana, o capitalismo começou a apresentar sinais de uma grande crise estrutural ${ }^{4}$. Os traços mais evidentes desta crise foram:

1) queda da taxa de lucro, dada, dentre outros elementos causais, pelo aumento do preço da força de trabalho [...] 2), o esgotamento do padrão de acumulação taylorista/fordista de produção, dada pela incapacidade de responder a retração do consumo que se acentuava. [...] 3) hipertrofia da esfera financeira, que ganhava relativa autonomia frente aos capitais produtivos, [...] 4) a maior concentração de capitais graças às fusões entre empresas monopolistas e oligopolistas; [...] 5) a crise do welfare state ou do "Estado do bem-estar social" e dos seus mecanismos de funcionamento, acarretando a crise fiscal do Estado capitalista e a necessidade de retração dos gastos públicos e sua transferência para o capital privado; 6) incremento acentuado das privatizações, tendência generalizada às desregulamentações e à flexibilização do processo produtivo, dos mercados e da força de trabalho (ANTUNES, 1999 p. 29-30).

Para Harvey (2010) esta crise deixava clara a incapacidade do fordismo e do keynesianismo de conter as contradições inerentes ao capitalismo. Segundo ele, as dificuldades deste modelo econômico tinham suas raízes na "[...] rigidez dos investimentos de capital fixo, [...] rigidez nos mercados, na alocação e nos contratos de trabalho, [...] [além da] rigidez dos compromissos do Estado" (HARVEY, 2010, p135).

O processo produtivo dominante neste período era o taylorista-fordista, que se consolidou como a forma mais racionalizada de produção em quase todo o século XX. No entanto, este modelo produtivo começava apresentar no final dos anos 60 e início dos anos 70, limites substanciais, que caracterizavam o seu esgotamento, o que levou o capital a buscar alternativas que dessem maior dinamicidade ao processo produtivo, culminando na transição do padrão de acumulação taylorista e fordista, (denominada por Harvey de acumulação rígida) para as novas formas de acumulação flexibilizada (ANTUNES, 1999).

O mesmo autor indica que o sistema taylorista/fordista de produção tinha como "[...] base a produção em massa de mercadorias, que se estruturava a partir de uma produção mais homogeneizada e enormemente verticalizada." (ANTUNES, 1999, p. 36). Neste sistema as indústrias concentravam na sede a maior parte da produção necessária para a fabricação da mercadoria, dentro da

\footnotetext{
${ }^{4}$ Antunes (1999, p.29-30) enumera alguns sinais do quadro crítico em que se encontra o capitalismo. Também indica em nota de rodapé (idem, p.30) Mészáros (1995) e Chesnais(1996) para uma análise mais aprofundada sobre a crise estrutural do capital.
} 
própria empresa, recorrendo apenas secundariamente ao fornecimento externo. Também identifica como característica deste processo a racionalização das operações realizadas pelos trabalhadores (característica taylorista do processo), com o objetivo de evitar ao máximo o desperdício na produção, reduzindo o tempo de produção e aumentando o ritmo de trabalho, visando intensificar a exploração sob as suas formas de mais valia absoluta e relativa.

As bases estruturais desse padrão produtivo foram assim expostas por Antunes (1999, p.37):

\footnotetext{
Esse padrão produtivo estruturou-se com base no trabalho parcelar e fragmentado, na decomposição das tarefas, que reduzida a ação resultava no trabalho coletivo produtor de veículos. Paralelamente à perda de destreza do labor do operário anterior, esse processo de desantropomorfização do trabalho e sua conversão em apêndice da máquina-ferramenta dotavam 0 capital de maior intensidade na extração do sobretrabalho. À mais valia extraída extensivamente, pelo prolongamento da jornada de trabalho e do acréscimo da sua dimensão absoluta, intensificava-se de modo prevalecente a sua extração intensiva, dada pela dimensão relativa da mais valia.
}

Este processo constituía-se de uma linha rígida de produção, que articulava os diferentes trabalhos individuais interligadas através da esteira que determinava o ritmo e o tempo de produção. Sendo estes, entre outros fatores, que caracterizaram este binômio taylorismo/fordismo, ou seja, a produção em série fordista e o cronômetro taylorista; além da separação entre a elaboração e a execução (ANTUNES, 1999).

Para o capital, este processo produtivo "tratava-se de apropriar-se do savoir faire do trabalho, "suprimindo" a dimensão intelectual do trabalho operário, que era transferida para as esferas da gerência científica" (ANTUNES, 1999, p. 37). Segundo Braverman (1987, p.82), a gerência científica foi um movimento iniciado por Frederick Winslow Taylor no final do século XIX, e significa de forma geral em um "empenho de aplicar os métodos da ciência aos problemas complexos e crescentes do controle do trabalho". Taylor expressa esta gerência científica em três princípios, denominados por Braverman, da seguinte forma: o primeiro, - dissociação do processo de trabalho das especialidades dos trabalhadores - todo o conhecimento fica a cargo do administrador; a segunda, separação da concepção e execução - os operários somente como executores do trabalho idealizado pela gerência científica; o terceiro, - é a utilização do 
monopólio do conhecimento para controlar cada fase do processo de trabalho (BRAVERMAN,1987, p. 103, 107).

Esta separação entre o trabalho instrumental e o intelectual, identifica a dualidade estrutural deste processo. No âmbito educacional no Brasil, esta dualidade expressou-se na oferta de escolas de formação profissional e escolas acadêmicas, que evidentemente atendiam a classes sociais distintas, com fins também distintos (KUENZER, 2007).

Para Antunes (1999) esta forma organizacional científica taylorista, bem como a fusão com o processo de produção fordista, teve no início da década de 70 a sua estrutura comprometida. A situação crítica que se estalará com a crise do padrão de acumulação taylorista/fordista, fez emergir o denominado toyotismo, e a era da acumulação flexível $\left.\right|^{5}$; que segundo Harvey (2010), trata-se de uma forma de acumulação apoiada na "flexibilidade dos processos, dos mercados de trabalho, dos produtos e padrões de consumo" (p. 140).

A vulnerabilidade do padrão de acumulação taylorista/fordista como característica fenomênica da crise, fez com que o capital implementasse um vasto processo de reestruturação produtiva, por meio da constituição das formas de acumulação flexível. Estas implementações resultaram em várias transformações no processo de trabalho, mediados pelo aumento de inovação tecnológica, comercial, e de gestão organizacional (ANTUNES, 1999).

O padrão de acumulação flexível articula um conjunto de elementos que apresentam características relativamente distintas do padrão taylorista/fordista ${ }^{6}$ de acumulação.

Ele se fundamenta num padrão produtivo organizacional e tecnologicamente avançado,
resultado da introdução de técnicas de gestão da força de trabalho próprias da fase
informacional, bem como da introdução ampliada dos computadores no processo
produtivo e de serviços. Desenvolve-se em uma estrutura mais flexível, recorrendo
freqüentemente à desconcentração produtiva, [opondo-se ao processo de
homogeneização característico do processo produtivo taylorista/fordista] às empresas
terceirizadas etc. Utiliza-se de novas técnicas de gestão da força de trabalho, do trabalho
em equipe, das "células de produção" dos "times de trabalho", dos grupos "semi-
autônomos", além de requerer, ao menos no plano discursivo o "envolvimento

\footnotetext{
5 Acumulação flexível, conceituação elaborada por Harvey que identifica uma nova forma de acumulação do capital, que se opõem a forma rígida de acumulação fordista.

6 Harvey (2010, p.167-169) apresenta uma tabela elaborada por Swyngedouw que identifica os contrastes no - processo de produção - trabalho - espaço - Estado e ideologia entre o fordismo e a acumulação flexível.
} 
participativo" dos trabalhadores, em verdade uma participação manipuladora e que preserva, na essência, as condições do trabalho alienado e estranhado. $O$ "trabalho polivalente", "multifuncional", "qualificado", combinado com uma estrutura mais horizontalizada e integrada entre diversas empresas, inclusive nas empresas terceirizadas, tem como finalidade a redução do tempo de trabalho [mais valia relativa] (ANTUNES, 1999, p. 52 grifo dos autores)

Antunes (1999), afirma que toda essa transformação no processo de reorganização do capital, e do processo de reestruturação do trabalho, que caracteriza a forma de acumulação flexível, tem como finalidade a redução do tempo de trabalho necessário, isto é, assegura este autor, tem a "[...] finalidade essencial, real, (...) a intensificação das condições de exploração da força de trabalho, reduzindo muito ou eliminando tanto o trabalho improdutivo, que não cria valor". (ANTUNES,1999, p. 53). A redução do tempo de trabalho necessário reflete a exploração da mais valia relativa, que se constitui da diminuição deste tempo de trabalho, e no conseqüente aumento do tempo de trabalho excedente. Logo, podemos concluir que todo este processo de reestruturação consiste fundamentalmente na exploração cada vez mais geométrica da mais valia relativa, que é central no capitalismo.

Segundo Antunes (1999), no processo industrial toyotista, a intensificação da exploração do trabalho acontece tanto pelo fato dos trabalhadores operarem simultaneamente varias máquinas, como pelo ritmo e velocidade da cadeia produtiva; o que caracteriza a exploração da mais valia por meio da mais valia relativa; e não só a mais valia relativa, mas também, a exploração da mais valia absoluta, isto é, pelo aumento da jornada de trabalho, o que foi proposto pelo governo japonês. Assim para Antunes (1999 p56), o toyotismo "[...] reinaugura um novo patamar de intensificação do trabalho, combinando fortemente as formas de mais valia absoluta e relativa".

O mesmo autor apresenta os contornos mais gerais, os traços determinantes deste modelo de produção toyotista:

1)é uma produção muito vinculada à demanda, visando atender às exigências mais individualizadas do mercado(...); 2) fundamenta-se no trabalho operário em equipe, com multivariedade de funções $(. .$.$) ; 3) a produção se estrutura em processo de produtivo$ flexível, que possibilita ao operário operar simultaneamente varias máquinas(...); 4) tem como princípio o Just in time, o melhor aproveitamento possível do tempo de produção(...); 5) No toyotismo os estoques são mínimos comparados com o fordismo $(. .) ; 6$.$) as empresas do complexo produtivo toyotista, inclusive as terceirizadas,$ 
têm uma estrutura horizontalizada, ao contrário da verticalidade fordista. Enquanto na fábrica fordista aproximadamente $75 \%$ da produção era realizada no seu interior, a fábrica toyotista é responsável por somente $25 \%(\ldots) ; 7)$ organiza os Círculos de Controle de Qualidade(...); 8) o toyotismo implantou o "emprego vitalício" para uma parcela dos trabalhadores das grandes empresas (ANTUNES, 1999 p54, 55).

Dentre estes elementos que constitui, ou, como aponta Harvey (2010), caracteriza este processo de acumulação flexível destaca-se, sobretudo, o aumento intensificado de inovação comercial, tecnológica e organizacional.

Estas formas de inovação resultaram em inúmeras transformações no processo de trabalho, e conseqüentemente na formação da força de trabalho. Por esta razão faremos uma breve introdução sobre a inovação nesta nova fase do capitalismo denominada de acumulação flexível, em que o processo de produção toyotista se mostrou mais adaptável, como também o aumento de produtividade advindo desta nova base tecnológica, e a relação de ambas com a exploração de mais valia relativa.

\section{Inovação, produtividade e mais valia relativa}

No documento da CNI A indústria e o Brasil uma agenda para crescer mais e melhor (CNI, 2010), a inovação aparece com um papel central para o desenvolvimento da produtividade econômica do país. O texto afirma que as empresas brasileiras dependem cada vez mais da capacidade de assimilar e produzir inovações para manterem a sustentação do crescimento e da competitividade, cada vez mais global e acirrada. Este documento ainda ressalta que a inovação é o motor gerador do aumento de produtividade, e que esta é a peça-chave para o crescimento da competitividade industrial. Segundo Carvalho (1994), o aumento da produtividade, assim como a melhora da qualidade e a conquista de novos mercados, depende crescentemente da capacidade tecnológica de firma e países. Isto explica porque para o Movimento empresarial pela inovação - MEI - a inovação é prioridade para a Indústria (CNI, 2010).

A CNI realizou em 19 de agosto de 2009 em São Paulo, o $3^{\circ}$ Congresso de Inovação na Indústria. Neste congresso foi apresentado um documento intitulado - Inovação: a construção do futuro, que apresenta a seguinte definição sobre inovação, "[...] a inovação é a agregação de qualidade, mas não 
só. É a incorporação de tecnologia, mas não só. Inovação é o requisito para uma economia competitiva, próspera e sustentável, com maior produtividade, com melhores empregos e salários" (CNI, 2009, p.5). Estas características da inovação do processo de trabalho têm sido confrontadas com uma realidade um tanto quanto distinta, se observamos o mercado de trabalho.

Harvey (2010) assinala que, o que de fato há, neste novo processo produtivo mediado pela inovação, é um grupo cada vez menor de trabalhadores estratégicos, que são muito bem qualificados, e treinados para exercerem funções de desenvolvimento tecnológico e administrativo nas corporações, que recebem bons salários; e outro tanto de trabalhadores, isto é a maioria, em condições precárias de trabalho, em atividades muitas vezes sub-humanos.

Numa análise de Gounet (1999) sobre este novo processo produtivo, que tem como articulador a inovação, também fica claro o estralhamento do significado atribuído pela MEI sobre inovação e trabalhador. Ele declara que este processo:

\footnotetext{
Permite maior exploração dos trabalhadores [porque] [...] intensifica o trabalho, sobrecarregando ao máximo cada operário. [que] [...] deve ser mais rápido, deve reduzir todos os "tempos mortos", [...] deve cumprir novas tarefas, como controle de qualidade ou a manutenção corrente das máquinas. [...] reduz os salários e degrada a proteção social nas fábricas, apoiando-se na tercerização (GOUNET, 1999 p.8, grifo dos autores).
}

Ele continua, dizendo que o capitalismo sobrevive fundamentalmente da exploração dos trabalhadores. Quanto mais o capitalismo avança, mais os empresários se empenham em introduzirem inovações, que permitam aumentar "a contribuição de cada trabalhador para a criação de riqueza" (GOUNET,1999, p.9). Esta criação de riqueza, refere-se à possibilidade do capital de extração de mais valia. Isto fica ainda mais claro ao observarmos o conceito de inovação: “[...] uso, aplicação e transformação do conhecimento técnico e científico em problemas relacionados com a produção e com a comercialização, tendo o lucro como perspectiva" (CASTILHOS, apud Technology Economy Programme, 1997, p.132). 
Enfim, todo implemento tecnológico utilizado em benefício do capital terá, como principio estrutural, a ampliação da capacidade de exploração de mais valia relativa, o que caracteriza a subsunção real do capital sobre o trabalho.

Com vimos no final do segundo tópico, Harvey (2010) apresenta três formas de inovação que estão concomitantemente ligadas. Parafraseando estas formas de inovação com a explicação de Gounet (1992) sobre estes novos métodos de produção toyotista, podemos dizer que a inovação comercial alicerçada na flexibilidade do aparato produtivo e nas flutuações de produção, exige consequentemente uma maior flexibilidade na organização do trabalho, isto é, inovações no plano organizacional.

Dentre essas formas de inovação, dedicaremos maior atenção à inovação tecnológica no processo produtivo, no chão da fábrica, tendo em vista que nos propusemos a analisar a educação do trabalhador adaptado a essas novas demandas industriais, através do discurso do empresariado industrial brasileiro.

De forma geral, a inovação comercial refere-se à primeira introdução de um novo produto ou um novo processo; a inovação organizacional trata de alterações nos processos de gestão e organização da produção; e a inovação tecnológica no processo de produção, corresponde à introdução de equipamentos de base microeletrônica, que incidem neste processo de produção, bem como no produto (CATTANI, 1997).

Sobre as inovações organizacionais, Machado (1994, p.175) assegura que estas "[...] trazem formas mais participativas, integradas, grupais, descentralizadas, autônomas, envolvente e flexível, mas não significa que sejam, por isso democráticas". Contrário a esta posição, este processo participativo tem como finalidade a captura da subjetividade operária.

Se o fordismo expropriou e transferiu o savoir-faire do operário para a esfera da gerência científica, para os níveis de elaboração, o toyotismo tende a re-transferi-lo para a força de trabalho, mas o faz visando a apropriar-se crescentemente da sua dimensão intelectual, das suas capacidades cognitivas, procurando envolver mais forte e intensamente a subjetividade operária. Os trabalhos em equipes, os círculos de controle, as sugestões oriundas do chão da fábrica, são recolhidos e apropriados pelo capital nessa fase de reestruturação produtiva. Suas idéias são absorvidas pelas empresas, após uma análise e comprovação de sua exeqüibilidade e vantagem (lucrativa) para o capital (ANTUNES, ALVES, 2004, p.347). 
Esta característica do modelo japonês o torna distinto do modelo fordista na relação capital-trabalho. No modelo toyotista, há a "revalorização" do saber intelectual do trabalhador. Esta revalorização justifica-se pela importância que as sugestões dos trabalhadores implicam em incorporações de inovação no processo produtivo (CATTANI, 1997).

A inovação tecnológica significa, no processo de reestruturação produtiva da indústria e de serviços, a introdução da automação de base microeletrônica, que correspondem a um vasto número de equipamentos, que têm como característica comum o fato de se conectarem a um computador que controla as operações das máquinas-ferramentas e os processos de dados. Dos equipamentos desta nova base tecnológica, destaca-se: $1^{\circ}$ Comando Numérico Computadorizado (CNC); $2^{\circ}$ Controle Lógico Programável (CLP); $3^{\circ}$ Robô; $4^{\circ} \mathrm{O}$ sistema de CAD/CAM (SILVA, 1997).

Esta implementação tecnológica de base microeletrônica, requer um novo tipo de tarefa dos trabalhadores. Os sistemas automatizados ao mesmo tempo em que "libera" o trabalhador produtivo de muitas tarefas repetitivas; exige deste, um conhecimento ligado a todo o sistema produtivo e a necessidade de anteciparse e corrigir as disfunções do sistema.

\begin{abstract}
Numa organização onde o ritmo da mudança tecnológica está sendo acelerado, a habilidade da força de trabalho para se adaptar rapidamente a novas "campanhas" de produção pode ser importante fator de competitividade. Face à intensificação da competição com base na inovação tecnológica, o conhecimento acumulado dos trabalhadores é uma fonte crucial de inovações incrementais, que não pode ser subestimada. O acompanhamento de sistemas automatizados que estão evoluindo e sempre apresentam falhas inesperadas requer uma mão-de-obra responsável, atenta e conhecedora dos equipamentos (CARVALHO, 1994, p. 101).
\end{abstract}

Isto significa que nesta nova base tecnológica do capitalismo contemporâneo as empresas requerem dos trabalhadores uma maior capacidade de abstração, percepção, adaptação e qualidades comportamentais relacionadas com a confiança e a cooperação (CARVALHO, 1994).

Assim, o processo de inovação tecnológica requer uma maior participação do trabalho operário, maior envolvimento no processo de produção, tanto em função da capacidade de adapta-se mais rapidamente as inovações, quanto pelo fato de conhecerem todo o processo produtivo, e poderem através de sugestões, 
contribuírem (cooperarem) para o incremento tecnológico da indústria. O que faz do saber intelectual do trabalhador um importante fator de competitividade.

No entanto, para que fosse possível esta participação operária, era preciso romper com processo de trabalho rígido e a divisão intelectual do trabalho presentes nos dogmas tayloristas. O toyotismo estabelece uma nova relação entre os setores de produção e o setores de desenvolvimento e gerência; uma relação que acontece na articulação entre a venda, o P \& D e a área de produção, isto é o chão da fábrica. Carvalho (1994) justifica que ao fazer assim, a empresa terá melhor resultados. Se o trabalhador individual ou o grupo passar a ter maior responsabilidade, autonomia e meios para se comunicar com outros setores da empresa, as soluções de problemas, bem como, o aproveitamento do conhecimento acumulado dos trabalhadores será mais rapidamente aproveitados.

Nas economias mais avançadas já é possível perceber o enfraquecimento do modelo de gestão taylorista. Nos padrões mais flexíveis, as gerências estão mudando, dando maior importância a criatividade e conhecimento da força de trabalho que constituem uma contribuição extremamente aceitável para as empresas no que diz respeito à eficiência, a qualidade e a inovação (CARVALHO, 1994).

Mas, esta contribuição acaba por configurar uma relação de antagonismo e exploração. O trabalhador contribuindo para ser ainda mais explorado, tendo em vista, que conforme assinala Amorim e Frederico (2008), na relação que estabelece entre a subsunção do capital sobre o trabalho, mediado pelo aumento da taxa de inovação; a criatividade, que é uma característica da força de trabalho, e a inovação, resultado na forma de mercadoria desta criatividade, são imprescindíveis para a acumulação do capitalista. Segundo Antunes, a apropriação "[...] da subjetividade operária é uma das precondições do próprio desenvolvimento da nova materialidade do capital" (2004, p.346).

$\mathrm{Na}$ verdade, todo este processo de adaptação do trabalhador, e de revalorização do saber intelectual, das novas formas produtivas tem como característica essencial a exploração da mais valia relativa:

Na verdade, a introdução da maquinaria complexa, das novas máquinas informatizadas que se tornam inteligentes, ou seja, o surgimento de uma nova base técnica do sistema 
sociometabólico do capital, que propicia um novo salto da subsunção real [exploração da mais valia relativa] do trabalho ao capital, exige, como pressuposto formal ineliminável, os princípios do toyotismo, no qual a captura da subjetividade operária é uma das precondições do próprio desenvolvimento da nova materialidade do capital. As novas tecnologias microeletrônicas na produção, capazes de promover um novo salto na produtividade do trabalho, exigiriam, como pressuposto formal, 0 novo envolvimento do trabalho vivo na produção capitalista (ANTUNES, ALVES 2004, p. 346 grifo dos autores).

Este envolvimento do trabalho vivo na produção, explica, o porquê dos discursos sobre uma maior participação operária - as políticas de formação continuada - as exigências de maior interação do trabalhador com todo o processo produtivo, a capacidade de abstração, percepção, e a valorização do saber acumulado dos trabalhadores, além de uma educação de qualidade.

A constatação de que o baixo nível de escolaridade constitui uma barreira efetiva à ampliação da reprodução do capital, fez com que as políticas educacionais passassem a ser um campo de disputas hegemônicas, e nesta disputa tem prevalecido os interesses da classe dominante.

\begin{abstract}
A educação, que poderia ser uma alavanca essencial para a mudança, tornou-se instrumento daqueles estigmas da sociedade capitalista [...] tornou-se uma peça do processo de acumulação do capital e de estabelecimento de um consenso que torna possível a reprodução do injusto sistema de classes. Em lugar de instrumento da emancipação humana, agora é mecanismo de perpetuação e reprodução desse sistema (SADER 2005, p.15).
\end{abstract}

No próximo tópico analisaremos a relação entre trabalho e educação no capitalismo contemporâneo observando o papel da escola neste discurso de formação de profissionais flexíveis. No primeiro momento apresentaremos uma síntese geral das transformações no âmbito educacional nesta forma de acumulação flexível identificando a sua relação com a exploração de mais valia relativa; em seguida, as perspectivas do empresariado brasileiro com relação à formação do trabalhador adaptado as novas bases tecnológicas.

\title{
A relação trabalho e a educação no capitalismo contemporâneo: flexiblidade como forma de exploração da mais-valia relativa
}

Em todas as fases de desenvolvimento do capitalismo, foi necessária uma formação de trabalho adequada para aquele determinado momento histórico. No taylorismo/fordismo, que por quase todo o século $\mathrm{XX}$ se mostrou como o processo 
de produção mais racionalizado, a formação de um novo tipo de homem capaz de se adaptar aos novos métodos da produção, implicou em uma nova perspectiva educacional; tratava de uma perspectiva de articulação de novas competências e novos modos de viver, adequados aos métodos de trabalho caracterizado pela automação, isto é, a ausência de utilização de energias intelectuais e da criatividade no desempenho do trabalho (KUENZER, 2007).

O processo de trabalho desta nova fase de produção capitalista é marcado como vimos anteriormente, pela fragmentação; separação entre trabalho instrumental e intelectual. $E$ isto significou no sistema de ensino uma dualidade estrutural, expressada "[...] pela oferta de escolas que se diferenciavam conforme a classe social que se propunham a formar: trabalhadores ou burgueses" (KUENZER, 2007, p.1156). Isto significou no sistema educacional brasileiro, escolas de formação profissional e escolas acadêmicas, que evidentemente atendiam a classes sociais distintas, com fins também distintos, expressando assim essa dimensão da dualidade estrutural.

A delimitação de funções, típicas das formas tayloristas/fordistas de organizar o trabalho, como as operacionais, técnicas, de gestão, bem como as de desenvolvimento de ciência e tecnologia, manifestava "[...] a clara definição de trajetórias educativas diferenciadas que atendessem às necessidades de disciplinamento dos trabalhadores e dirigentes (KUENZER, 2007, p. 1156).

Para este processo produtivo caracterizado pela fragmentação, e por uma tecnológica de base predominantemente eletromecânica, bastava somente uma educação profissional especializada, parcial, que tivesse o foco na ocupação e no cumprimento sistemático dos procedimentos "[...] a serem repetidos por meio de processos pedagógicos que privilegiavam a memorização; não havia, portanto, no trabalho de natureza operacional, necessidade de escolarização ampliada, uma vez que não havia necessidades significativas de trabalho intelectual neste nível" (KUENZER, 2007, p.1157).

O processo de produção toyotista, conforme já assinalamos acima, caracterizado pela flexibilidade, por uma base tecnológica informacional e microeletrônica, apresentou novas experiências na organização industrial, e consequentemente no processo de trabalho; o que implicou em novas formas de 
disciplinamento da força de trabalho.

Kuenzer (2007, p. 1159) afirma:

Estas novas formas de disciplinamento vão contemplar o desenvolvimento de subjetividades que atendam às exigências da produção e da vida social, mas também se submetam aos processos flexíveis caracterizados pela intensificação e pela precarização, a configurar o consumo cada vez mais predatório e desumano da força de trabalho. Para atender a estas demandas, o discurso da acumulação flexível sobre a educação aponta para a necessidade da formação de profissionais flexíveis, que acompanhem as mudanças tecnológicas decorrentes da dinamicidade da produção científico-tecnológica contemporânea, ao invés de profissionais rígidos, que repetem procedimentos memorizados ou recriados por meio da experiência. Para que esta formação flexível seja possível, torna-se necessário substituir a formação especializada, adquirida em cursos profissionalizantes focados em ocupações parciais e, geralmente, de curta duração, complementados pela formação no trabalho, pela formação geral adquirida por meio de escolarização ampliada, que abranja no mínimo a educação básica, a ser disponibilizada para todos os trabalhadores.

Assim, a partir da formação geral mais sólida, dar-se-á a formação profissional, tendo como princípio um caráter mais abrangente do que especializado. A proposta é de substituição da estabilidade, da rigidez, pelo movimento, e dinamicidade, cabendo à educação o papel de assegurar o domínio dos conhecimentos que norteiam as práticas sociais e a capacidade de trabalhar com ele. Tendo como pressuposto, a categoria central da pedagogia da acumulação flexível, que é o desenvolvimento de competências que possibilite aprender ao longo da vida. Isto se justifica pela dinâmica, ou ainda pela própria materialidade deste regime de acumulação. Se o trabalhador transitará, ao longo de sua vida, por varias ocupações e também por inúmeras oportunidades de educação profissional, não há razão em investir em uma formação profissional especializada. Neste discurso pedagógico, ressalta Kuenzer (2007, p.1159), "[...] a integração entre as trajetórias de escolaridade e laboral resultará na articulação entre teoria e prática, resgatando-se, desta forma, a unidade rompida pela clássica forma de divisão técnica do trabalho, que atribuía a uns o trabalho operacional, simplificado, e a outros o trabalho intelectual, complexo.

É nesta perspectiva que é lançada as bases da proposta de superação desta dualidade estrutural, em que se destaca o sistema escolar, que se sistematizou em ofertar um único caminho, de natureza geral, assegurados para todos, até o final da educação básica (KUENZER, 2007).

Os pressupostos que fundamentam a possibilidade de superação da 
dualidade estrutural neste novo regime de acumulação flexível, vêem no enfretamento de eventos, conseqüência da vulnerabilidade desta nova base tecnológica, o caminho para a superação. A explicação, afirma Kuenzer (2007), seria porque este enfrentamento culminaria em ações que resultaria na articulação entre percepções, conhecimentos teóricos e tácitos, que, resgataria a unidade corpo/intelecto, trabalho manual e intelectual, prática e teoria. Isto equivale a dizer que, os desafios desta nova base tecnológicos, que exigi a utilização das capacidades cognitivas mais complexas, isto é, o trabalho intelectual, e correspondentemente a valorização da educação escolar, contrariando ao que ocorria no taylorismo/fordismo, de não valorização da educação para execução do trabalho, a possibilidade de superação desta dualidade. No entanto, esta concepção compreende o trabalho somente na dimensão prático individual, e não o trabalho no seu sentido ontológico, e, portanto, insuficiente para superação desta dualidade, antes pelo contrário: "[...] a acumulação flexível expressa a forma histórica contemporânea de existência do modo de produção capitalista, cuja a essência continua sendo a contradição entre a propriedade privada dos meios de produção e a venda da força de trabalho, embora assuma múltiplas e variadas formas de materialização" (KUENZER, 2007, p.1164).

O que há de novo nesta concepção, decorrente do regime de acumulação flexível, é que, tanto a produção, como o consumo, passam a demandar uma relação com o conhecimento sistematizado, isto é, "[...] de natureza teórica, mediada pelo domínio de competências cognitivas complexas, (...) e para o domínio da lógica formal, que não era demandada pelo taylorismo/fordismo, cuja concepção de conhecimento fundava-se na dimensão tácita: resolver situações pouco complexas por meio de ações aprendidas através da experiência" (KUENZER, 2007, p.1160). No toyotismo, conforme apreendemos em Antunes (1999), a captura da subjetividade operária, é uma precondição para esta nova materialidade do capital, e isto explica, por exemplo, o porquê da ênfase do setor industrial brasileiro sobre a qualidade da educação básica, isto é, do domínio do conhecimento sistematizado para o desenvolvimento e competitividade do país.

Temos ressaltado até aqui, que a reestruturação produtiva tem refletido de 
forma impactante na formação do trabalhador. A necessidade de se formar um trabalhador flexível vai além da adaptabilidade a esta nova base microeletrônica. Esta nova organização do trabalho ressalta Kuenzer (2007), significa um maior controle sobre o trabalho, maior exploração tanto de mais valia absoluta quanto relativa. Esta formação de profissionais flexíveis relega a educação o papel de disciplinamento, e dualidade, por ter uma ação diferenciada para cada núcleo de trabalhadores necessários para os novos métodos de acumulação desta nova fase do capitalismo.

Kuenzer (2007) afirma:

\begin{abstract}
As empresas, para enfrentarem a competição, assegurando razoável margem de lucro, mantêm um núcleo duro de trabalhadores estáveis, com boas condições de trabalho, política generosa de benefícios e oportunidades de qualificação permanente, para assegurar capacidade de adaptação a novas exigências do trabalho, inclusive mobilidade geográfica.(...) Para além deste núcleo central, temos os grupos periféricos, compostos por trabalhadores cujas competências são facilmente encontradas no mercado e por toda a sorte de trabalhadores temporários e subcontratados, que apresentam baixa qualificação e alta rotatividade, uma vez que são incluídos/excluídos de ocupações precarizadas e intensificadas ao sabor das necessidades do mercado. Neste caso, a flexibilidade resulta da permanente movimentação de uma força de trabalho desqualificada, (...) se, no caso dos trabalhadores do núcleo duro, a flexibilização resulta da qualificação, no caso dos trabalhadores periféricos ela resulta da desqualificação. Para a formação/disciplinamento destes dois grupos, a educação básica atua de modo diferenciado: para os primeiros, assume caráter propedêutico, a ser complementada com formação científico-tecnológica e sóciohistórica avançada. Para os demais, assume o caráter de preparação geral que viabiliza treinamentos aligeirados, com foco nas diferentes ocupações em que serão inseridos ao longo das trajetórias laborais, em diferentes pontos de distintas cadeias produtivas; de todo modo, nestes casos, a educação básica, completa ou, na maioria das vezes, incompleta, resulta em formação final e contribui para a flexibilidade por meio da desqualificação (KUENZER, 2007 p1164-1165 grifo dos autores).
\end{abstract}

Isto denota a educação, conforme ressalta Frigotto (1995), o seu caráter de segregação e exclusão. Nesta síntese da relação trabalho e educação nesta nova fase do capitalismo é possível perceber como cada vez mais a intensificação da exploração de mais valia é central nesta forma de organização social. Não é de mais lembrar, que é a exploração desta força de trabalho, ou ainda, a intensificação cada vez maior de exploração desta força, que se concebe 0 capitalismo. 


\section{O papel da educação para a formação do trabalhador adaptado às novas formas de produção de base técnica microeletrônica na perspectiva do empresariado industrial brasileiro}

Para Silva (1994), no processo de produção taylorista/fordista os anseios da oferta educacional no Brasil proposta pelos educadores e as necessidades da demanda, isto é, do processo industrial, eram conflitantes. A escola única com qualidade igual para todos não se fazia necessária, pois na primeira etapa do processo de industrialização do país foi possível estabelecer um parque industrial razoável, e contar com uma base estreita de mão de obra qualificada aliada a um contingente enorme de trabalhadores com baixa educação e mal preparados para enfrentar desafios mais complexos. Hoje, no entanto, aponta Silva (1994), a realidade se mostra completamente diferente; as indústrias brasileiras possuem, mesmo que em um nível menor do que alguns países desenvolvidos, uma base técnica com alta tecnologia de produção e informação, o que impõe ao país uma nova condição de competitividade internacional, mediada pelo estabelecimento de um sistema educacional onde tanto a força de trabalho, como o restante da população precisam de no mínimo de 8 a 10 séries de ensino de boa qualidade.

Este ensino de qualidade para todos deve formar trabalhadores que integre mais rapidamente as transformações do contexto atual, isto é, formar indivíduos que no mínimo saibam:

ler, interpretar a realidade, expressar-se adequadamente, lidar com conceitos científicos e matemáticos abstratos, trabalhar em grupos na resolução de problemas relativamente complexos, entender e usufruir das potencialidades tecnológicas do mundo que nos cerca. E, principalmente, precisa aprender a aprender, condição indispensável para poder acompanhar as mudanças e avanços cada vez mais rápidos que caracterizam o ritmo da sociedade moderna (SILVA FILHO, 1994, p 87).

O novo padrão de produção intensificado pelo aumento das novas tecnologias, e de novas técnicas de gestão a elas associadas, exigiram a recuperação da "inteligência da produção", que antes era vista como ruído indesejável dentro do paradigma taylorista. Coube a educação o papel de proporcionar o desenvolvimento de capacidades cognitivas mais complexas, que 
permitam uma ação direta do trabalhador no processo de produção (CARVALHO, 1994).

Esta nova base técnica, cada vez mais alicerçada na microeletrônica e no processo informacional implicou ao trabalhador a utilização da sua capacidade de abstração em função deste novo padrão tecnológico. A razão, é que este sistema pode apresentar problemas que comprometem todo o processo de produção, e para evitar tais problemas, seria preciso uma intervenção direta do trabalhador com capacidade de analisar e agir em situações imprevistas. Saber trabalhar em equipe, também passa a ser uma questão fundamental, por isto, se torna uma exigência para este novo trabalhador. $O$ motivo está no fato destes sistemas estarem interligados, o que significa que os problemas não atingem somente um setor do processo de produção, mas todo o processo produtivo, o que demanda uma maior interação entre os trabalhadores para solucionar estes problemas (FRIGOTTO, 1995).

Como podemos observar este novo processo de produção industrial, estruturada na microeletrônica apresenta uma vulnerabilidade tecnológica, que demanda uma intervenção do trabalhador, com uma capacidade cognitiva mais complexa, diferente do período da automação do fordismo, e isto segundo Frigotto (1995, p. 154), identifica que o processo em que o capital estar, não "[...] prescinde do saber do trabalhador e do saber do trabalho e é forçado a demandar trabalhadores com um nível de capacitação teórico mais elevado, o que implica mais tempo de escolaridade e de melhor qualidade"

Cônscio desta situação o empresariado industrial brasileiro representado pela CNI - Confederação Nacional da Indústria, elaborou no ano de 2007 um programa denominado Educação Para a Nova Indústria - uma ação para o desenvolvimento sustentável do Brasil. Neste programa, é apresentada, uma proposta de ação sobre a formação do trabalhador adaptado a essas novas formas de organização do processo de trabalho na nova base produtiva. $O$ documento enfatiza a importância da educação no papel competitivo do país. Na apresentação deste documento o presidente da CNI ressalta os desafios da formação educacional deste novo trabalhador frente aos avanços tecnológicos, e justifica a proposta afirmando que: 
O Brasil concorre com nações que não param de investir na qualidade do ensino, caso de vários países da Ásia, Europa do Norte e América Central. O momento é de inflexão. O desafio que se apresenta é o de expandir a oferta de oportunidades de formação de recursos humanos com alta qualidade. Essa ação deve estar alicerçada em significativo aporte de investimentos em recursos humanos e infra-estrutura e ser movida por inovações nos conteúdos, nas tecnologias da informação e da comunicação, sintonizada com os novos paradigmas educacionais (CNI - Educação Para a Nova Industria, 2007 p8).

O texto ainda ressalta que as contínuas transformações nos processos produtivos, em especial da incorporação crescente de tecnologia, resultaram em progressivas e significativas variações nas competências necessárias para 0 trabalho; o que demanda um novo perfil de trabalhador para a indústria. Uma força de trabalho com maior escolaridade, tanto em nível médio e superior, quanto de tecnólogos. O baixo nível de escolaridade dos trabalhadores é um dos principais limitadores do crescimento no País. Em função das inovações tecnológicas no processo produtivo, a formação dos novos profissionais exige mais investimento em modernização da infra-estrutura tecnológica das escolas e dos seus laboratórios. Ainda enfatiza que esta nova realidade da indústria requer uma educação continuada, isto é, a aprendizagem ao longo da vida, de ambiente mais flexível, tanto no formato, como nos conteúdos (CNI, 2007).

Com relação à organização do sistema de ensino, o documento toma como referência a tendência internacional, que é a de, inicialmente, priorizar os cursos de formação geral, para, posteriormente no âmbito da própria empresa, se fazer o aprofundamento da especialização, de acordo com as necessidades e exigências dos novos padrões tecnológicos. Declara que o trabalhador, isto é o capital humano nas organizações, é considerado na denominada sociedade do conhecimento como o principal ativo das empresas. E que, por ser este capital humano "[...] formado pelo conjunto de habilidades que as pessoas detêm, adquiridas por meio de processos educativos, treinamento ou da experiência"(CNI - Educação Para a Nova Industria, 2007, p.21) os processos educativos, aliados as experiências laboral são fundamentais para a industria. Ratificam que uma indústria competitiva depende da força de trabalho capacitada, qualificada, e, portanto, se faz necessário melhorar os índices de escolaridade do trabalhador e garantir aos seus filhos (prole) educação de qualidade (CNI, 2007). 
Ao observarmos a relação estabelecida entre o papel da educação no desenvolvimento competitivo do país, conforme pressupõe o documento citado acima, ou ainda, se, relacionamos os mentores e veiculadores da proposta de educação geral de qualidade, dos quais podemos citar o Banco Mundial, BID, UNESCO, OIT, podemos notar que "[...] tanto a integração econômica quanto à valorização da educação básica geral para formar trabalhadores com capacidade de abstração, polivalentes, flexíveis [...] ficam subordinados à lógica do mercado, do capital, e portanto, da diferenciação, segmentação e exclusão" (FRIGOTTO, 1995 p145).

\section{Considerações Finais}

Pretendeu-se neste artigo analisar os fundamentos da relação da inovação tecnológica com a exploração da mais relativa no capitalismo contemporâneo e o papel da educação na formação dos trabalhadores neste contexto, buscando identificar como o capital articula inovação, produtividade e projeto educacional.

Tendo em vista que a pesquisa tinha como pressuposto teórico um referencial marxista, e, portanto de relações entre trabalho e educação como parte da totalidade social, iniciou-se a análise observando o conceito de mais valia, por ser este um dos conceitos centrais para compreensão das determinações sociais nesta forma de organização social atual. Em seguida, o conceito de mais valia relativa, que têm como pré-condição a revolução dos meios de produção, especialmente a inovação tecnológica, alvo deste trabalho. Este conceito foi fundamental para estabelecer a relação entre inovação, produtividade, e exploração de mais valia.

A inovação é uma das bases desta nova fase de desenvolvimento capitalista definida como acumulação flexível. Este regime de acumulação deu-se como resposta à crise da fase fordista e do keynesianismo, como resultado de transformações em âmbito político, econômico e social. Extraiu-se para esta investigação somente as características da reestruturação produtiva e suas implicações no processo de trabalho, em especial ao aumento das implementações tecnológicas, como sendo uma modalidade para o aumento de 
produtividade, e consequentemente de exploração de mais valia relativa.

Este aumento intensificado de inovação resultou em inúmeras mudanças comerciais, organizacionais, e tecnológicas no processo de produção. Observouse que estas mudanças acabaram por intensificar a utilização da força de trabalho, resultando em precarização, desqualificação e exploração cada vez maior de mais valia.

As inovações tecnológicas de base microeletrônica e informacional exigiram como pressuposto formal, um outro tipo de envolvimento do trabalho vivo, o que resulta em uma nova formação da força de trabalho, isto é, uma mão de obra mais bem qualificada, capacitada e flexível, capaz de utilizar da sua capacidade de abstração em função deste novo padrão tecnológico. Por esta razão, a CNI elaborou uma proposta educacional que articula inovação e educação básica para atender a estas novas características da indústria brasileira. Ou seja, coube à educação o papel de desenvolvimento das competências necessárias a esta nova base tecnológica.

Apreendeu-se que a educação básica apresenta-se de forma diferente para cada núcleo de trabalhadores desta fase de acumulação; para uns significou qualificação, e iniciação a formação científico-tecnológico, enquanto para outros uma educação básica de formação geral, que geralmente resulta na formação final. Identificou-se ainda que neste discurso de formação de profissionais flexíveis há necessariamente uma relação de exploração de mais valia relativa.

Enfim, conclui-se que através do estudo da relação capital, trabalho e educação, é possível entender o que a inovação realmente significa numa proposta educacional. A inovação proporcionou formas de intensificação da utilização da força de trabalho, possibilitou o ápice da exploração, unindo eficazmente a exploração por meio da mais valia absoluta e relativa. O que levounos a refletir se um projeto educacional que tem como proposta a articulação entre inovação e educação não acaba conferindo uma prática pedagógica que manifesta o seu estranhamento por continuar a serviço da lógica do capital, de conformação a exploração?

A análise do discurso empresarial industrial brasileiro sobre a educação básica nesta nova fase de desenvolvimento capitalista evidencia que esta 
"preocupação" com a educação está relacionada com a capacidade do país de se tornar mais competitivo. Esta competitividade refere-se à introdução de novos produtos, de novos processos e acima de tudo, de novas tecnologias que permitam a diminuição dos custos com a manutenção da força de trabalho, ou seja, tem a finalidade de ampliar a exploração da mais valia relativa. Logo um projeto educacional que tem a ênfase na adaptação da força de trabalho a esta nova base tecnológica, está condicionada mais uma vez em todos estes anos de educação institucionalizada a legitimação e continuidade deste sistema injusto, desigual e degradante.

O projeto educacional proposto pelo empresariado, como estratégia para educação brasileira, inclusive a pública, possui uma concepção de educação que representa os seus interesses, logo, de perpetuação das relações de classe. Portanto, o estudo desta proposta é uma análise fundamental para uma estratégia maior de conscientização para um projeto socialista. Entendo que a educação tem um papel essencial na transformação social, e no desenvolvimento desta consciência.

\section{Referências}

AMORIM, M. C. S.; FREDERICO, R. Criatividade, inovação e controle nas organizações. Revista de Ciências Humanas, Florianópolis, EDUFSC, v. 42, n. 1 e 2, p. 75-89, Abril e Outubro de 2008. Disponível em: <http://www.cfh.ufsc.br/ revista/rch42/RCH42_artigo_3.pdf>. Acesso em $30 \mathrm{de}$ abril de 2011.

ANTUNES, R. Os sentidos do trabalho: ensaio sobre a afirmação e a negação do trabalho. São Paulo: Boitempo, 1999. (Coleção mundo do trabalho).

ANTUNES, R.; ALVES, G. As mutações no mundo do trabalho na era da mundialização do capital. Educ. Soc. [online]. 2004, vol.25, n.87, pp. 335-351. Dsponível em: < http://www.scielo.br/pdf/es/v25n87/21460.pdf>. Acesso em 11 de junho de 2011.

BRAVERMAN, H. Trabalho e capital monopolista: a degradação do trabalho no século XX. 3. ed. Rio de Janeiro: LTC, 1987.

BOTTOMORE, T. Dicionário do pensamento marxista. Rio de Janeiro: Zahar, 1988. 
CARCANHOLO, R. Sobre o conceito de mais-valia extra em Marx (versão preliminar). V Encontro Nacional de Economia Política. Fortaleza: 21 a 23 de junho de 2000.

CARVALHO, R. de Q. Capacitação tecnológica, revalorização do trabalho e educação. In: FERRETI, C. J. et al (Org.). Novas tecnologias, trabalho e educação: um debate multidisciplinar. 9 ed. Petrópolis, RJ: Vozes, 1994.

CONFEDERAÇÃO NACIONAL DA INDÚSTRIA. Mapa Estratégico da Indústria. Brasília: CNI, 2005.

Educação Para a Nova Indústria: uma ação para o desenvolvimento sustentável do Brasil/ Confederação Nacional da Indústria, Serviço Social da Indústria, Serviço Nacional de Aprendizagem Industrial.- Brasília: CNI, 2007. $\overline{\mathrm{CNI}}, 2010$.

A indústria e o Brasil: uma agenda para crescer mais e melhor. Brasília:

SILVA FILHO, H. P. de F e. O empresariado e a educação. In: FERRETI, C. J. et al (Org.).Novas tecnologias, trabalho e educação: um debate multidisciplinar. 9 ed. Petrópolis, RJ: Vozes, 1994.

FRIGOTTO, G. Educação e a crise do capitalismo real. 3 ed. São Paulo: Cortez, 1999.

GOUNET, T. Fordismo e toyotismo na civilização do automóvel. São Paulo: Boitempo Editorial, 1999.

HARVEY, D. Condição pós-moderna. 17.ed. São Paulo: Loyola, 2010. p.121134.

KUENZER, A. Z. Da dualidade assumida à dualidade negada: o discurso da flexibilização justifica a inclusão excludente. Educação e Sociedade. vol.28. no 100 Campinas oct.2007. Disponível em: < http://www.scielo.br/pdf/es/v28n100/a2428100.pdf>. Acesso em 15 de maio de 2011.

KUENZER, A.Z.; ABREU, C. B.; GOMES, C. M. A. A articulação entre conhecimento tácito e inovação tecnológica: a função mediadora da educação. Revista Brasileira Educação, Dez. 2007, vol.12, no.36, p.462-473. ISSN 14132478.

MACHADO, L. R. de S. A educação e os desafios das novas tecnologias. In: FERRETI, C. J. et al (Org.). Novas tecnologias, trabalho e educação: um debate multidisciplinar. 9. ed. Petrópolis, RJ: Vozes, 1994.

MARX, K. O capital: crítica da economia política. Volume 1. Rio de Janeiro: Civilização Brasileira, 1989.

MARX, K. O capital: crítica da economia política. Volume 2. Rio de Janeiro: Civilização Brasileira, 1989.

MELO, A. A Redução Ontológica do Homem à máquina em Marx: subsídios ao debate contemporâneo. Educação em Revista. vol.25. no 02. Belo Horizonte. Aug.2009. ISSN 0102-4698. Disponível em:<http://www.scielo.br/scielo.php?script=sci_arttext\&pid=S0102- 
$46982009000200007 \&$ Ing=en\&nrm=iso\&tlng=pt> Acesso em 13 out. 2009.

O Projeto Pedagógico da Confederação Nacional da Indústria Para a Educação Básica nos anos 2000. Tese (doutorado em Educação), Programa de Pós-Graduação em Educação, Universidade Federal do Paraná, Curitiba, 2010. $260 f$.

MESZÁROS, I. A educação para além do capital. 2 ed. São Paulo: Boitempo, 2008

SADER, E. Prefácio. In: MÉSZÁROS, I. A educação para além do capital. 2 ed. São Paulo: Boitempo, 2008.

SILVA, L. H. Novas Tecnológicas. In: CATTANI, A. D. Et al (Org.). Trabalho e Tecnologia: dicionário critico. Petrópolis: Vozes, 1997.

TUMOLO, P. S. O trabalho na forma social do capital e o trabalho como princípio educativo: uma articulação possível? Educ. Soc. [online]. 2005, vol.26, n.90, pp. 239-265. Disponível em: $<$ http://www.scielo.br/pdf/es/v26n90/a11v2690.pdf>. Acesso em 20 de abril de 2011. 